\title{
A INFLUÊNCIA DO NEOCONSERVADORISMO NOS ESTUDOS DE GÊNERO NO
} BRASIL

\author{
Paulo Roberto de Souza Junior ${ }^{1}$
}

\section{RESUMO:}

Este artigo enfoca a influência do neoconservadorismo dentro dos estudos de gênero. A omissão desses estudos dentro da legislação educacional, como o PNE e a BNCC, poderá acarretar prejuízos aos grupos socialmente vilipendiados. Há necessidade de uma (re)avaliação desta influência como forma de possibilitar caminhos que privilegiem tais estudos para viabilizar o respeito a elas e as suas diferenças. A metodologia utilizada foi a de pesquisa bibliográfica, em que os resultados permitem concluir que há necessidade deste enfretamento para garantir o respeito à diversidade sexual em sociedade.

PALAVRAS-CHAVE: estudos de gênero; neoconservadorismo; neofundamentalismo; educação; legislação.

\section{THE INFLUENCE OF NEOCONSERVATISM ON GENDER STUDIES IN BRAZIL}

\section{ABSTRACT:}

His article focuses on the influence of neoconservatism within gender studies. The omission of these studies within the educational legislation, such as PNE and BNCC, may cause harm to socially vilified groups. There is a need for a (re) evaluation of this influence to enable ways that privilege such studies to enable respect for them and their differences. The methodology used was bibliographic research, in which the results allow us to conclude that there is a need for this confrontation to ensure respect for sexual diversity in society.

KEYWORDS: gender studies; conservatism; fundamentalism; education; legislation.

\section{1- Introdução}

Este artigo traz como preocupação central a omissão dos estudos de gênero dentro do (neo)conservadorismo, devido a necessidade de se preservar o respeito à diversidade sexual entre os educandos. Trata-se de um debate acerca da ideologia política e suas consequências no ambiente escolar no Brasil.

\footnotetext{
${ }^{1}$ Graduação em Direito pela UGF (1991), Mestrado em Direito pela UNESA (2000). Membro do Comitê de Pareceristas da Revista de Direito da Cidade (QUALIS: A1) e da Revista Publicum. Especialista em Pós Graduação em Gênero e Sexualidades - FAVENI / UNYLEYA (2019), Gestão da Saúde Pública, Direito Constitucional, Direito Tributário e Gestão Hospitalar. Autor de obras e artigos jurídicos. Professor de Direito e Legislação da FAETEC/RJ e da SEEDUC/RJ. Experiência em graduação e pós (especialização) e conteudista EAD (edição de livros, material escolar, parecerista - MEI). pauloroberto.coordenacao@gmail.com
} 
Desta forma, temos como hipótese a seguinte afirmação: a avaliação de políticas educacionais, em tempos atuais, que não privilegiam os estudos de gênero, ou seja, a influência do (neo)conservadorismo e o (neo)fundamentalismo ${ }^{2}{ }^{3}$ dentro das construções sociais definidas pelos estudos de gênero.

No Dicionário de política, de Bobbio, Matteucci e Pasquino (2000), o termo conservadorismo designa "ideias e atitudes que visam à manutenção do sistema político existente e dos seus modos de funcionamento, apresentando-se como contraponto das forças inovadoras" (BONAZZI, 2000, p. 243).

Os neoconservadores contemporâneos são caracterizados na esfera política, como salientado por Álvaro Bianchi (2016):

[...] a tentativa de conciliar o autoritarismo próprio da antiga tradição com a democracia representativa, estabelecendo, porém, fortes limites ao funcionamento desta. O caráter plebiscitário da democracia limitada e poder moderador atribuído crescentemente ao Judiciário deveriam garantir que o exercício do sufrágio universal não se traduzisse plenamente na realização da soberania popular. As paixões populares e os interesses dos grupos socais poderiam, assim, permanecer à margem da política, sendo convocados periodicamente apenas para escolher a facção governante. A concepção elitista da política, que sempre acompanhou o conservadorismo, traduziu-se, assim, em uma concepção elitista da democracia representativa" (BIANCHI, 2016, p. 19).

O neoconservadorismo não possue características próprias e se alimentam do ódio aos que não comungam com suas ideias ou dogmas, assim, podendo, como mencionado, colocar em perigo a luta pela igualdade de direitos que se busca a incluir na legislação em análise, já que visam enfraquecer qualquer tentativa de manifestação progressista e, por conseguinte, a garantia de direitos em prol de pessoas que não se afinam a uma relação tradicional de gênero.

\footnotetext{
${ }^{2} \mathrm{O}$ termo "fundamentalismo" refere-se à "(...)interpretação literal das revelações do livro sagrado, sejam elas cristãs ou islâmicas, tomada com o princípio estruturante de organização da sociedade, social e política" (Savi, 2015, p.12). O fundamentalismo religioso alega prejuízos morais causados pelos valores seculares, recusando a diversidade moral, cultural e de subjetividade, reivindicando o retorno de práticas sociais tradicionais. Assim, surge como força de oposição à secularização (Chauí,2006; Lionço, 2017; Savi, 2015).

${ }^{3}$ Para losurdo (2006, p. 109-110), apesar de suas diferenças, o neoconservadorismo e o neoliberalismo acabam encontrando-se com a velha e a nova direita "na liquidação, não apenas do movimento socialista, mas da herança da revolução francesa e da ideia de igualdade, do estado providência". o autor vai ainda mais longe ao afirmar que a destruição da herança do movimento democrático-socialista "não pode deixar de colidir com o conceito de homem e de direitos do homem como tal" (losurdo, 2006 , p. 110), com seus direitos universais. (Editores da Revista Educação \& Sociedade, 2017).
} 
A influência deste "pensamento fundamentalista e (neo)conservador" é, na verdade, o conjunto de teorias que versam sobre a questão da "ideologia de gênero, conceito criado pela Igreja Católica e aceito pelas Igrejas Pentecostais no Brasil, como forma de respeito à família tradicional que não permite que as escolas tratem de questões ligadas ao gênero e a diversidade sexual.

Este conceito inicialmente tratado por escritoras católicas, antifeministas, foi absorvido pela Cúria Romana, que viu nele uma forma de desestruturação do matrimônio e, por conseguinte, da família tradicional e dos afazes conjugais da mulher.

Relacionamos várias tentativas de obstrução aos estudos de gênero na atualidade, salientando que ele é considerado como uma ideologia "diabólica e marxista", como aconteceu em 2016, onde ele foi impactado, negativamente, o acordo pela Paz na Colômbia, como mencionado por Marco Aurélio Máximo Prado e Sonia Correa (2018).

E, por fim, a ida ao segundo turno das eleições presidenciais, na França, de um candidato de extra direita, a chegada ao poder na Colômbia de um conservador, que fez o Congresso adiar a aprovação do regulamento da Justiça Especial para a Paz (JEP) e o discurso, do Sr. Jair Bolsonaro, em 2019, destinado ao Congresso Nacional, como um de seus objetivos, será o combate a "ideologia e gênero".

O gênero possui atributos performativos, a prática do dia a dia e o reconhecimento dos papéis que o ser humano desenvolve em sociedade. Assim gênero é feito todos os dias, onde seu papel inclui tudo o que uma pessoa diz ou faz para se revelar a si própria como possuidora de condição de moça/rapaz; homem/mulher, inclui a sexualidade.

Neste contexto, procuramos discutir as reproduções não aceitas pelo (neo)conservadorismo dentro dos estudos de gêneros.

Entretanto, sem a presente discussão fica visível a possibilidade de violência de gênero e a discriminação sexual no âmbito escolar as quais podem se manifestar por meio de ameaças, agressões físicas, constrangimentos, assédio sexual e/ou moral e abusos sexuais e estupros. Não sendo outro o entendimento de Guacira Lopes Louro (2003):

[...] meninos e meninas aprendem, também desde muito cedo, piadas e gozações, apelidos e gestos para dirigirem àqueles e àquelas que não se ajustam aos padrões de gênero e de sexualidade admitidos na cultura em que vivemll (LOURO, 2003, p. 29). 
A principal justificativa deste trabalho é o enfrentamento daquela ideologia política que busca a não permissão dos estudos de gênero por entender que se trata de uma "ideologia de gênero", conceito criado pela Igreja Católica para discordar destes estudos propostos pelo movimento feminista de segunda onda e acatados pela ONU - Organização das Nações Unidas.

O instrumento utilizado dentro deste estudo será a pesquisa bibliográfica sobre a temática, onde serão apreciados estudos de artigos, PNE - Plano Nacional da Educação e a BNCC - Base Nacional Curricular Comum, na busca de condições para sintetizar uma análise correta e coerente desta política com finalidade de traçar os referidos caminhos para sua revisão. O texto final foi fundamentado nas ideias e concepções de autores como, BIANCHI (2016), SOUZA Jr (2018) e SEPULVEDA e SEPULVEDA (2018)

\section{2- Os Estudos de gênero}

A cultura define as características dos corpos e os distingue através do gênero e suas marcas sociais, dentre as quais identificamos a classe, a raça/etnia, a sexualidade, a geração, a religião e a nacionalidade.

É dentro destes espaços que o gênero é visto, já que é tido como uma construção social, onde há uma gama de interesses em que transitam os termos masculinos e femininos, não tendo a ver com uma ou genitália, pois são relacionados à performance, à prática do dia a dia.

\section{1 - Os Estudos de gênero}

O gênero possui atributos performativos, a prática do dia a dia e onde seu papel inclui tudo o que uma pessoa diz ou faz para se revelar a si própria como possuidora de condição de moça/rapaz; homem/mulher.

O inventor do conceito de gênero ou "gender" foi o psicólogo John Money, segundo Rafael C. Fornasier, citando Tony Anatrella, no prefácio da obra de Olivier Bonnewijn (2015):

O inventor do termo "gender" é um psicólogo americano, John Money, que nos anos 50 afirmava que a diferença homem-mulher é devida 
mais à educação do que biológico. Acompanha-o em seu pensar o psicanalista Robert Stoller, principal inventor da ideia de separação entre sexo e gênero (1960). O sexo aparece como marca do espaço corporal sem outra consequência sobre a vida psíquica, enquanto o gênero é ao mesmo tempo a identidade sexual assinalada pela sociedade (o masculino e o feminismo) e o que o sujeito vai escolher em sua orientação sexual. Ele poderá, assim, ter uma identidade heterossexual, bissexual, homossexual ou transexual e eventualmente mudar (FORNASIER apud ANATRELLA, 2015, p. 7).

Notamos que durante a história mundial, a relação binária de gênero é posicionada entre homens e mulheres, ou seja, há uma heteronormatividade ${ }^{4}$.

Os estudos de gênero são observados durante a segunda e a terceira onda do feminismo; aquela foi marcada por Simone de Beauvoir (1980); e está por Angela Davis e Bell Hooks. Estes visam uma ruptura da relação binária de gênero, apoiando-se na desconstrução da identidade de gênero ${ }^{5}$ com a finalidade de preservar a performance de gênero.

Joan Scott em seu artigo "Gênero: uma categoria útil de análise", na American Historical Review, em 1986, publicado em português em 1990, propôs o gênero como uma categoria de análise e não como um tema ou um objeto.

Esse movimento "investiga a organização social tendo como ponto de partida as desigualdades de gênero" (MIGUEL; BIROLI, 2014, p.8), problematizando, assim, as diferenças biológicas atribuídas à natureza dos sexos e a demanda e a autonomia das mulheres. Tais relações atuam na sociedade e, por conseguinte, não estão destinadas somente a elas.

A influência feminista, a partir de 1970, trouxe à baila um debate sobre a questão de gênero e sua interseccionalidade ${ }^{6}$ com outros marcadores sociais da diferença e da

\footnotetext{
${ }^{4}$ Trata-se de uma palavracomposta pelos vocábulos hetero e norma. O termo hetero significa outro, diferente, ou seja, o antônimo de homo, que significa igual. De modo sucinto, ainda seguindo o raciocínio de Luís Henrique Sacchi dos Santos (2007), podemos tomar o termo hetero em relação à sexualidade, a palavra heterossexual diz respeito à atração que uma pessoa sente por outra(s) de sexo diferente do seu, enquanto que a palavra homossexual diz respeito a atração que uma pessoa sente por outra(s) do mesmo sexo. (PETRY E MEYER, 2011, p. 196).

${ }^{5}$ Identidade de gênero consiste no modo como o indivíduo se identifica com o seu gênero. Em suma, representa como a pessoa se reconhece: homem, mulher, ambos ou nenhum dos gêneros. https://www.significados.com.br/identidade-de-genero/acesso em 19 de ago de 2019).

${ }^{6}$ E pensada como uma categoria teórica que focaliza múltiplos sistemas de opressão, em particular, articulando raça, gênero e classe ( SOUZA, Maciana de Freitas e. O que é interseccionalidade?". 1 de julho de 2019. http://www.justificando.com/2019/07/01/o-que-e-interseccionalidade/acesso em 19 de ago de 2011).
} 
desigualdade, tais como classe, raça, etnia, geração, orientação sexual, identidade de gênero (SOUZA Jr, 2018, p. 9).

E, por fim, a terceira onda que se refere a década de 1990, onde "gênero e sexo passam a ser criticados como discursos normativos que conferem sustentação ao dispositivo binário de gênero, que por sua vez representa um mecanismo de hierarquização e de controle social" (LANS, 2015, p. 48).

Nesta década nasce o grupo riot grrrl (garotas rebeldes, em tradução livre), que pautavam questões como estupro, sexualidade, patriarcado e empoderamento feminino.

\section{1 - Ideologia de gênero como ferramenta da negação dos estudos de gênero}

A criação do conceito "ideologia de gênero" deu-se através da Igreja Católica, a qual se insurgiu contra o debate de questões de gênero proposto pela Segunda Onda do Feminismo e abraçada pela ONU (Organização Nações Unidas) nas Conferências de Cairo e Pequim, em 1994 e 1995, respectivamente.

Em 1998, o Papa João Paulo II $^{7}$ estava preocupado com a questão sobre a influência do conceito de gênero sobre a "família tradicional", a "verdadeira feminilidade" ou a "verdadeira masculinidade" e, por isso, divulgou a encíclica (carta apostólica) intitulada "Sobre a dignidade e a vocação da mulher" (Mulieris dignitatem), onde lembrava a todos o papel da mulher para a maternidade e que suas funções eram diversas aos homens.

Após esta nota, a presente temática foi abordada pela Cúria Romana, através do Conselho Pontifício para a Família, em 26 de julho de 2000, que versava sobre a Família, Matrimônio e "uniões de fato" salientando que o uso desta temática busca a desestruturação cultural e humana da instituição matrimonial, pois libertam o uso das identidades sexuais e de gênero como desejam as pessoas e o natural, pela lei divina, é "a categoria da identidade genérica sexual (“gender”), portanto de ordem psicossocial e cultural.

Ela corresponde e está em harmonia com a identidade sexual de ordem psicobiológica, quando a integração da personalidade se realiza como reconhecimento da plenitude da verdade interior da pessoa, unidade de alma e corpo" (PONTIFICIO, Conselho para a Família, 2000, s/p.).

\footnotetext{
7 Papa da Igreja Católica, nome de batismo Karol Wojtyła. O início de seu pontificado deu-se em 22 de outubro de 1978 e seu término foi em 02 de abril de 2005 (http://www.vatican.va/holy_father/john_paul_ii/index_po.htm, acesso em 19 de ago de 2019).
} 
O Conselho Pontifício para a Família, sob a presidência do cardeal Alfonso López Trujillo, que é um opositor a Teologia da Libertação, contrário ao uso de preservativos, ao casamento homossexual etc, publica um extenso dicionário enciclopédico sobre a temática, em 2003, intitulado Lexicon: termos ambíguos e discutidos sobre a família, vida e questões éticas (PONTIFICIO Conselho para a Família, 2006).

Rogério Diniz Junqueira (2018) assim se posiciona sobre ele:

[..] em relação à educação sexual, opta pela atenção a família e define os limites desta educação no âmbito escolar, além de se opor ao feminismo, onde define que sexo e sexualidade são elementos pertencentes à ordem transcendente, pré-social, natural e imutável (GARBAGNOLI, 2014 apud JUNQUEIRA, 2018)

Em 31 de maio de 2004, o Papa João Paulo II se pronunciou sobre a questão em "Carta aos bispos", onde se manifestou contra o discurso feminista, reiterando que a maternidade era um elemento-chave da identidade feminina.

Outro registro importante para a temática é a publicação, em 2010, da obra intitulada La ideologia de género o el género como herramienta de poder $^{8}$, por Jorge Scala, que é tida como referência por parte das autoridades católicas brasileiras para esta temática, além do I Congresso Internacional de Ideologia de Gênero com base no pensamento católico tradicionalista, ocorrido em fevereiro de 2011, na Universidade de Navarra.

Nesta mesma linha, e com maior crítica à teoria de gênero, em 2012, o Papa Bento $\mathrm{XVI}^{9}$ proferiu seu discurso de Natal, assim se posicionando:

De acordo com esta filosofia, o sexo já não é considerado um elemento dado pela Natureza e que o ser humano deve aceitar e estabelecer um sentido pessoal para a sua vida. Em vez disso, o sexo é considerado pela Ideologia de Género como um papel social escolhido pelo indivíduo, enquanto no passado, o sexo era escolhido para nós pela sociedade. A profunda falsidade desta teoria e a tentativa de uma revolução antropológica que ela contém, são óbvias. As pessoas [que promovem a Ideologia de Género] colocam em causa a ideia segundo a qual têm uma natureza que lhes é dada pela identidade corporal que serve como um elemento definidor do ser humano. Elas negam a sua

\footnotetext{
${ }^{8}$ A ideologia de gênero ou gênero como ferramenta de poder [tradução livre]

${ }^{9}$ Papa da Igreja Católica, nascido Joseph Aloisius Ratzinger, Seu papado iniciou-se em 19.04 .2005 e terminou com sua renúncia em 28 de fevereiro (https://w2.vatican.va/content/benedict-xvi/pt.html, acesso em 19 de ago de 2019).
} 
natureza e decidem que não é algo que lhes foi previamente dado, mas antes que é algo que elas próprias podem construir. (...) Quando a liberdade para sermos criativos se transforma em uma liberdade para nos criarmos a nós próprios, então é o próprio Criador que é necessariamente negado e, em última análise, o ser humano é despojado da sua dignidade enquanto criatura de Deus que tem a Sua imagem no âmago do seu ser. (...) A Ideologia de Género é uma moda muito negativa para a Humanidade, embora se disfarce com bons sentimentos e em nome de um alegado progresso, alegados direitos, ou em um alegado humanismo. Por isso, a Igreja Católica reafirma o seu assentimento em relação à dignidade e à beleza do casamento como uma expressão da aliança fiel e generosa entre uma mulher e um homem, e recusa e refuta as filosofias de género, porque a reciprocidade entre o homem e a mulher é a expressão da beleza da Natureza pretendida pelo Criador\|l (SOFOS, 2017).

Através deste discurso, a Igreja se posicionou sobre a temática e, por conseguinte, autorizou a difusão de seu posicionamento através dos meios de comunicação, originando, assim, um movimento antigênero dentro dos países que a Igreja Católica se faz presente.

Rafael Solano (2016) enumera três consequências em relação a "ideologia de gênero, na atualidade, quais sejam: negação da família; fortalecimento do relativismo; e, eliminação da pessoa (SOLANO, 2016, p. 33/38).

Para a Igreja Católica o erro fundamental da ideologia de gênero é a negação da natureza humana em matéria sexual (SCALA, 2011), fato mencionado por Pe. Luiz Carlos Lodi da Cruz no prefácio da obra de Jorge Scala (2011):

Não há, segundo tais ideólogos, um homem natural nem uma mulher natural. Masculinidade e feminilidade são meras construções sociais, que podem (ou devem) ser desconstruídas. O casamento entre um só homem e uma só mulher (heterossexualidade obrigatória) é visto não como a união natural entre dois seres complementares e fecundos, mas como mera convenção da sociedade. A família é uma instituição a ser abolida. Faz-se isso dando novo sentido a essa palavra. Família deixa de ser o "santuário da vida" e passa a designar qualquer aglomerado de pessoas (no futuro, também animais?), com qualquer tipo de comportamento sexual (incluindo a pedofilia?), orientado ou não à procriação. A vida deixa de ser sagrada, para ser o produto do encontro casual de um macho e uma fêmea da espécie humana. A promoção do aborto, portanto, é coerente com a defesa da desestruturação da família e faz parte da agenda de gênero. Ideologia de gênero (CRUZ, 2011). 


\section{3 - O (neo)conservadorismo: conceito e influência no Brasil}

$\mathrm{Na}$ esteira da nova ordem pós-colonial e pós-socialista do mundo e no contexto da sociedade de informação e da política neoliberal, há um questionamento radical do sistema binário de gênero, pois para que o projeto neoliberal tenha êxito, estudantes não devem apenas aprender os conteúdos nas aulas, mas também, e sobretudo, apreender o modo correto de viver em sociedade.

Segundo Stephen J. Ball (2014) "o neoliberalismo abrange [...] tanto as relações materiais quanto as sociais envolvidas, que são, ao mesmo tempo, o foco neomarxista sobre a economização ‘da vida social e da criação' de novas oportunidades de lucro” (BALL, 2014, p. 25).

Este neoliberalismo é oriundo da Terceira Revolução Industrial e Globalização tem como missão o desaparelhamento do Estado, pois é apenas necessário a este uma infraestrutura básica que servirá para a produção de mercadorias, a qual sintetiza o valor de uso e da troca. Havendo o excedente desta, a pessoa pode privar-se da mesma para venda ou quando esta não for sua poderá trocar trabalho por salário. As classes sociais começam a existir através desta ação.

O mundo conheceu esta ideologia antes do Brasil, através de dois governos: Margareth Thatcher, na Inglaterra e Ronald Reagan, nos Estados Unidos.

O centrismo liberal e a economia keynesiana ficaram subitamente fora de moda. Margaret Thatcher lançou o chamado neoliberalismo, que era na realidade um conservadorismo agressivo de um tipo que não era visto desde 1848, e que envolveu uma tentativa de reverter a redistribuição do Estado de Bem-Estar, de modo a beneficiar as classes superiores e não as classes mais baixas (WALLERSTEIN, 2004, p.61).

$\mathrm{Na}$ América Latina teve sua origem na crise do capitalismo dos anos 1960. Seus fundamentos são o anticomunismo da Guerra Fria e o repúdio das políticas públicas keynesianas, que atribuem um papel decisivo ao Estado no desenvolvimento econômico. Se para Keynes o desenvolvimento dependia de políticas sociais voltadas a assegurar o pleno emprego e a redistribuição da renda por meio do controle estatal de preços, da inflação e dos 
salários, para os neoliberais foi a oposição e a crítica a esses princípios que fez surgir sua doutrina (ROSENMANN, 2015).

Dentro deste caminho, o neoliberalismo entende que o Estado deve ser mínimo, combatendo os direitos sociais e os direitos dos grupos socialmente vilipendiados.

O mundo capitalista mergulhou na neoliberalização como a resposta por meio de uma serie de idas e vindas e de experimentos caóticos que na verdade só convergiram como uma onda ortodoxia com a articulação, nos anos 1990, do que veio a ser conhecido como o “Consenso de Washington" (HARVEY, 2014, p. 23).

Entretanto, esta onda neoliberal que foi abraçada pela elite burguesa se desenvolveu de forma parcial e assimétrica de Estado para Estado, ou seja, não houve uma forma a ser seguida entre estes Estados, pois dependeu de arranjos, tradições históricas e de sua força política.

Chega nos Estados Unidos uma onda conservadora atrelada a este neoliberalismo, em 1960, chamada de neoconservadorismo, onde incorpora princípios deste sem abrir mão do seu ideário e do seu modo específico de compreender a realidade, já que se apresenta como uma ordem conservadora do capitalismo.

Para entendermos o conceito de conservadorismo buscamos suporte em Denize Sepúlveda e José Antônio Sepúlveda (2018) que assim mencionam:

Entendemos o conservadorismo como uma visão social do mundo (LOW, 2000) cujo discurso se baseia no estilo de pensamento que Manhein (1959) chama de conservador e que tem um seu pilar a tradição. Sendo, assim, o discurso conservador se fundamenta no tradicionalismo inventado conforme perspectiva desenvolvida por Hobsbawn (1997), para construir uma agenda que se baseia na desigualdade social (SEPULVEDA e SEPULVEDA, 2018, p. 50).

Este neoconservadorismo surge diretamente da sensação de pertencimento a alguma ordem social contínua e preexistente e da percepção de que esse fato é importantíssimo para determinar o que fazer. A 'ordem' pode ser de um clube, de uma sociedade, a de uma classe, a de uma comunidade, a de uma igreja, a de um governo ou de uma nação (SCRUTON, 2015, p. 51), ou seja, busca-se a continuidade de seu mundo social, sem mudanças ou revoluções sociais para responder ao clamor da sociedade. 
A aprovação do Brexit na Inglaterra, a eleição de Donald Trump nos Estados Unidos, bem como as eleições na França, na Alemanha, na Áustria e, ainda mais recentemente, na Tchecoslováquia, confirmam essa tendência. O mesmo ocorre no Brasil e em diversos países da América Latina, seja no âmbito da formulação de políticas, seja na esfera das relações sociais e culturais. Entre nós, o projeto da reforma previdenciária, da Escola sem Partido ou a tentativa de silenciamento da filósofa americana Judith Butler são momentos expressivos dessa recente onda conservador (EDITORES DA REVISTA EDUCAÇÃO \& SOCIEDADE, 2017).

Somamos a isso, a chegada de Jair Bolsonaro ao governo brasileiro e a eleição de um grupo grande parlamentares que formam sua base na atual legislatura do Congresso Nacional.

Esclarece Maria Lúcia S. Barroco (2015), como nasceu o movimento neoconservador:

A origem do movimento neoconservador norte-americano é situada no pós-guerra, onde se destaca um grupo de intelectuais como Irving Kristol, Daniel Bell, Russell Kirk, entre outros. Nos anos 1960, manifestou sua reação à contracultura, aos movimentos de defesa de direitos das minorias, fortalecendo-se no contexto da implantação das políticas neoliberais, apresentando-se como programa político (a partir do governo Reagan) sustentado pela defesa do neoliberismo, do militarismo e dos valores tradicionais familiares e religiosos (BARROCO, 2015, p. 624).

\section{1 - A influência do (neo)conservadorismo no Brasil}

As novas direitas são heterogêneas e diversificadas, se intitulam "coletivistas metafísicas" e buscam criar uma "boa sociedade", atuando, para tanto, em diferentes contextos que são de seus interesses.

A novidade é uma inesperada capacidade de mobilização entre as diversas camadas sociais, já que se utilizam da questão de políticas penais como base em seu apelo popular, devido ao interesse da sociedade neste tipo demandas, gerando, assim, um grande aparato policial e repressivo, além da preocupação com a família tradicional, o alívio da pobreza e na geração de renda. 
Este neoconservadorismo se alimenta de crises políticas, econômicas, apontando para o "bandido", o qual identifica como a "esquerda", normalmente chamada de comunista, revolucionária, progressista, baderneira, entre outros adjetivos.

Sua chegada ao país é através de Fernando Henrique Cardoso e de sua equipe, o qual foi eleito por uma frente conservadora, onde participavam diversos segmentos da classe dominante, bem como a maioria da classe média e um número grande de pessoas da classe popular.

Buscava-se derrotar eleitoralmente a esquerda e implantar o programa político neoliberal, que defende um amplo programa de privatizações; uma reforma constitucional realizada com base no neoliberalismo (quebra de monopólios, saneamento da previdência social e da administração pública); e a abertura da economia ao capital internacional.

Nesta época, a onda neoconservadora (ou neocon) ainda não tinha grandes seguidores pelo Brasil, pois ela foi criada nos EUA, nos anos de 1960 para contradizer a ideologia da Nova Esquerda, propondo a rejeição ao liberalismo social, pacifismo, relativismo moral e da social democracia.

A presente corrente é carregada de problemas conceituais por se tratar de uma corrente sem qualquer base econômica, eleitoral ou religiosa de caráter fixo, como Gabriel Romero Lyra Trigueiro (2017) salienta em sua tese de doutoramento em História:

Aqui no entanto convém recordar que se a tradição neoconservadora, ao longo das décadas, foi se tornando cada vez mais intervencionista, internacionalista e militarista, havia igualmente amplos segmentos do movimento conservador norte-americano que iam na direção inversaao menos desde o início do século XX. Este era o caso, por exemplo da chamada Velha Direita(ou dos paleoconservadores, o segmento da tradição conservadora norte-americana que, ao criar a sua genealogia própria, se filiou filosoficamente à Velha Direita, em oposição aos demais segmentos do movimento conservador), uma franja do movimento conservador detentora de uma agenda antiintervencionista, anti-imigração e antiglobalização, bem diversa do cosmopolitismo e globalismo neocon, a propósito. O ponto principal da agenda da Velha Direita, e dos paleoconservadores, entretanto, era uma severa crítica ao forte militarismo, sobretudo no pós-Segunda Guerra Mundial-de modo suprapartidário, é bom salientar. Em comparação aos neoconservadores, a Velha Direita e os paleocons sempre receberam pouca atenção da mídia. Isso se explica sobretudo pelo fato de que enquanto os primeiros receberam grande escrutínio da imprensa no pós-11 de Setembro, sobretudo pelo fato de terem sido ligados com frequência ao governo Bush, o segundo grupo jamais alcançou o status de corrente majoritária, quer fosse dentro do 
movimento conservador, quer fosse no interior da máquina Republicana (TRIGUEIRO, 2017, p. 153).

Atualmente, este conceito se refere aos fundamentalistas religiosos ${ }^{10}$ presentes na política nacional, representantes da filosofia neopentecostal ou Terceira Onda do Pentecostalismo $^{11}$ que tem como base o movimento carismático, aliados aos (neo)conservadores, que não permitem abordagens sobre gênero, diversidade sexual e educação sexual dentro do ambiente escolar, devido a defesa das características da família tradicional heteronormativa.

Está onde neoconservadora atrelada ao fundamentalismo mencionado, onde se produz o pânico moral ${ }^{12}$ às pessoas que não o seguem, por criarem "dispositivos de poder e regime de verdade baseados no padrão burguês, branco, heterossexual e masculino (SEPULVEDA e SEPULVEDA, 2018, p. 50).

\section{4- A influência do neoconservadorismo em atividades escolares}

No contexto da educação nos deparamos com a padronização, privatização, competividade, controle, diminuição de recursos à educação pública, que são os eixos dos discursos neoliberais e neofundamentalistas. Para dar condições da realização do expediente relacionado, no Brasil, há a união da bancada fundamentalista religiosa com a bancada conservadora presente no Congresso Nacional.

${ }^{10} \mathrm{O}$ fundamentalismo refere-se a qualquer seita ou movimento dentro de uma religião que enfatize uma adesão rígida ao que concebe como princípios fundamentais de sua fé, geralmente resultando em uma denúncia de práticas e interpretações alternativas (Fundamentalismo religioso - Origem, Características e Críticas. Escola Educação. https://escolaeducacao.com.br/fundamentalismo-religiosol, acesso de 05 de ago de 2019).

${ }^{11}$ A Terceira Onda teve início no final dos anos 70 e início dos anos 80, e é fortemente caracterizada por um certo afastamento das doutrinas pentecostais clássicas e apego à chamada teologia da prosperidade. Os "Neo Pentecostais" como são chamados, adotam formas diferentes de administração e utilizam técnicas de Marketing extremamente eficazes em suas abordagens tendo na mídia seu principal foco. Desta terceira onda, surgiram a Igreja Universal do reino de Deus, Igreja Internacional da Graça de Deus, Igreja Mundial do Poder de Deus, Igreja Renascer em Cristo, Comunidade Sara Nossa Terra, Igreja Paz e Vida, as Comunidades Evangélicas em geral e diversas outras. O Foco da Mensagem é Prosperidade Financeira, bem-estar pessoal, exorcismo etc. (FERREIRA, Jorge A. As 03 Ondas do Pentecostalismo 'Resumo', 31 de maio de 2018, https://opentecostalreformado.blogspot.com/2018/05/as-03-ondas-do-pentecostalismo-resumo.html, acesso em 05 de ago de 2018).

${ }^{12}$ É um conceito de sociologia cunhado por Stanley Cohen, em 1972, para definir a reação de um grupo de pessoas baseada na percepção falsa ou empolada de que o comportamento de um determinado grupo, normalmente uma minoria ou uma subcultura, é perigoso e representa uma ameaça para a sociedade no seu todo (PONTES, David. A abrir - pânico moral. JN. 27 de abr de 2017, https://www.jn.pt/opiniao/davidpontes/interior/panico-moral-6234400.html, acesso em 18 de ago de 2019).

Revista de Gênero, Sexualidade e Direito | e-ISSN: 2525-9849 | Belém | v. 5 | n. 2 | p. 55 - 73 | Jul/Dez. 2019. 
Dentro desta união de bancadas há uma pauta forte que é a tentativa de inibição dos estudos de gênero dentro do ambiente escolar, argumentando que a família é soberana e responsável por tais questões.

Através deste posicionamento vem interferindo na aprovação de legislação educacional que versa sobre tais estudos, em todas as esferas legislativas, em especial, no PNE- Plano Nacional de Educação e na BNCC - Base Nacional Comum Curricular.

O Projeto de Lei $n^{\circ}$ 2010, que instituiu o Plano Nacional de Educação para decênio de 2011-2020, base da Conferência Nacional de 2010 e 2014, previa no item 3.9 a criação de uma rede de proteção aos LGBTs da exclusão do movimento, devido ao preconceito e discriminação à orientação e identidade de gênero.

Entretanto, ao tramitar sob o PL no 8035/2010, o referido item foi suprimido e assim publicado através da Lei Ordinária 13005/2016. Adriano Souza Senkevics comentou esta omissão:

Setores conservadores, mobilizados por políticos fundamentalistas, têm se oposto à votação do PNE em razão de sua menção à "igualdade de gênero". Nos termos dos obscurantistas, tratar-se-ia de uma "ideologia de gênero". [...] Esses grupos temem pela "destruição da família", os "valores e morais" alicerçados na "lei natural" e, evidentemente, o avanço das pautas LGBT, dentre as quais a diversidade sexual, a criminalização da homofobia e o progresso em torno da despatologização do segmento trans - pontos, na verdade, que transcendem a escola. (SENKEVICS, 2014, s/p.).

Em 2016, a BNCC começou a ser definida através de inúmeras agendas, as quais definiram o que e como os alunos iriam aprender a cada ano na educação básica.

Sua versão final foi revisada pelo MEC (Ministério da Educação) e encaminhada ao CNE (Conselho Nacional de Educação), no final de novembro de 2017, sem a previsão de debates "corpo, gênero e sexualidade nas tradições religiosas e definia que, nesse eixo, as escolas deveriam discutir as distintas concepções de gênero e sexualidade segundo diferentes tradições religiosas e filosofias de vida" (https://oglobo.globo.com/sociedade/educacao/cneretira-genero-orientacao-sexual-dabase-curricular-22179063\#ixzz5AHL1Gt00, acesso em 20.03.2018).

Após audiências regionais realizadas em Manaus, Recife, Florianópolis, São Paulo e Brasília, com caráter exclusivamente consultivo, o CNE publicou a Resolução CNE/CP $\mathrm{n}^{\circ}$ 2, datada de 22 de dezembro de 2017, que instituiu e orientou a implantação da Base Nacional 
Comum Curricular a ser respeitada obrigatoriamente ao longo das etapas e às respectivas modalidades no âmbito da Educação Básica.

A referida $\mathrm{BNCC}$ menciona que os componentes curriculares deverão respeitar a temática da diversidade determinada no Parecer CNE/CP no 11/2009 do CNE, entretanto, ao seguir os ditames do referido movimento, apresenta os mesmos problemas dos currículos da BNCC - Ensino Fundamental, ou seja, propõe um currículo tradicional, sem debates e posicionamentos acerca da cidadania, excluindo, assim, questões referentes às minorias sexuais, de gênero e até racial e, por conseguinte, retirando-os dos bancos escolares e da própria sociedade, devido suas performances.

Ao se pensar em performances identitárias nos deparamos com sujeitos que vivem e se apresentam de determinada forma socialmente, entretanto, devido à complexidade da vida, há necessidade que estes assumam diferentes identidades, as quais são criadas por marcadores de diferenciação, onde podemos incluir a: etnia, raça, gênero e sexualidade, entre outros fatores. Esta identidade "é um significado - cultural e socialmente atribuído" (SILVA, 2014, p. 89) ao sujeito em sociedade.

\section{5- Conclusão}

A escola é um local de relações sociais e neste local há necessidade de ser debatido os estudos de gênero, que é um conjunto de representações sociais, históricas e culturais, assim, não sendo determinados por estruturas. As pessoas constroem a si mesmas como masculinas ou femininas, reivindicando um lugar na ordem do gênero, às vezes misturados ou contraditórios.

Estes estudos datam da segunda onda do feminismo americano que se iniciou entre os anos 60 e 70, trazendo consigo a sua interseccionalidade com outros marcadores sociais da diferença e da desigualdade, tais como classe, raça, etnia, geração, orientação sexual, identidade de gênero. E, por fim, a terceira onda que se refere a década de 1990, onde criticam os discursos que resguardam a relação binária de gênero.

Esta temática foi abraçada pela ONU, nas Conferências do Cairo e de Pequim, 1994 e 1995 , respectivamente. 
Estes estudos de gênero não são aceitos pelos religiosos fundamentalistas por considerá-los como uma construção falsa, que negaria a verdade da diferença sexual. Com este jargão tentam garantir que os padrões dominantes e historicamente naturalizados de estruturação da realidade não sejam alterados.

Coube a Igreja Católica dá o passo inicial para questionar tais debates, onde tanto o Papa João Paulo II, como Bento XVI, proferiram debates que abertamente discutiam tais estudos, chamando-os de "ideologia de gênero", em nome da família tradicional e heterossexual.

Este conceito criado pela Igreja Católica e aceito pelas Igrejas Pentecostais no Brasil, como forma de respeito à família tradicional que não permite que as escolas tratem de questões ligadas ao gênero e a diversidade sexual.

Atualmente, há uma união do pensamento fundamentalista com neoconservadorismo, onde questionam os estudos sobre o gênero. Tal posicionamento está presente tanto no PNE como BNCC, pois ao silenciar-se sobre a temática, autorizam o seu não-debate e, por conseguinte, acatam o previsto como "ideologia de gênero".

Diante disso, devemos sim questioná-los como forma de proporcionar condições de seu debate visando o respeito aos direitos dos grupos socialmente vilipendiados.

\section{Referências Bibliográficas}

BALL, Stephen J. Educação Global S. A.: novas redes de políticas e o imaginário neoliberal. Tradução de Janete Bridon. Ponta Grossa: UEPG, 2014

BARROCO, Maria Lúcia S. Não passarão! Ofensiva neoconservadora e Serviço Social.IN: Serv. Soc. Soc., São Paulo, n. 124, p. 623-636, out./dez. 2015

BENTO XVI. Discurso à Cúria Romana por Ocasião dos Votos de Feliz Natal. Cidade do Vaticano, 22 dez. 2008.

BENTO XVI. Discurso à Cúria Romana por Ocasião dos Votos na Apresentação de Votos Natalícios. Cidade do Vaticano, 21 dez. 2012.

BIANCHI, Alvaro. Neoconservadorismo, Neoliberalismo e Neofundamentalismo. In: Revista CULT. Ano 19, dezembro, 2016, pp.18 a 21. 
BONAZZI, T. Conservadorismo. In: BOBBIO, N.; MATTEUCCI, N.; PASQUINO, G. (Orgs.). Dicionário de política. Brasília: Editora da UnB; São Paulo: Imprensa Oficial, 2000. V. 1. p. 242-246.

BRASIL. Ministério da Educação. Base Nacional Comum Curricular: 2a versão. 2016. < www.historiadabncc.mec.gov.br/documentos/bncc-2versa o.revista.pdf >. Acesso em 05/02/2019.

CONGREGAÇÃO para a Doutrina da Fé. Carta aos Bisposda Igreja Católica sobre a Colaboração do Homem e da Mulher na Igreja e no Mundo. Roma, 31 maio, 2004. Disponível em: <goo.gl/8q0Gno>. [Port.: goo.gl/qpjBrl]. Acesso em: 10 ago. 2019

CRUZ, Luiz Carlos Lodi da. Apresentação. IN: SCALA, Jorge Ideologia de Gênero: neototalitarismo e a morte da família. São Paulo/RJ: Katechesis, 2011

EDITORES DA REVISTA EDUCAÇÃO \& SOCIEDADE. Neoconservadorismo, educação e privação de direitos. IN: Educ. Soc. vol.38 no.141 Campinas Oct./Dec. 2017. http://www.scielo.br/scielo.php?script=sci_arttext\&pid=S0101-73302017000400865, acesso em 30 ago 2019.

FERREIRA, Jorge A. As 03 Ondas do Pentecostalismo 'Resumo', 31 de maio de 2018, https://opentecostal-reformado.blogspot.com/2018/05/as-03-ondas-do-pentecostalismoresumo.html, acesso em 05 de ago de 2018

FORNASIER. Rafael C. Prefácio. In: BONNEWINJ, Olivier. Gender, Quem és tu? - Sobre ideologia de gênero. Campinas-SP: Ecclesiae, 2015, p. 7-16.

HARVEY, David. O neoliberalismo: história e implicações. Trad. Adail Sobral, Maria Stela Gonçalves. 5ả. São Paulo: Edições Loyola, 2014.

JOÃO PAULO II. Carta às Famílias - Gratissimam sane. Roma, 2 fev. 1994. Disponível em: <goo.g1/2YxJ97>. [Port.: goo.g1/5X4R53]. Acesso em: 10 set. 2015.

JUNQUEIRA, Rogério Diniz. "Ideologia de gênero": A gênese de uma categoria política reacionária - ou: a promoção dos direitos humanos se tornou uma "ameaça à família natural"? IN: RIBEIRO, Paula Regina Costa e MAGALHÃES, Joanalira Corpes. Debates contemporâneos sobre Educação para a sexualidade. Rio Grande: Ed. da FURG, 2017, p. 25 a

http://repositorio.furg.br/bitstream/handle/1/7097/debates contemporaneos educacao sexuali dade.pdf?sequence=1, acesso em: 31 jul 2019. 
A invenção da "ideologia de gênero": a emergência de um cenário político-discursivo e a elaboração de uma retórica reacionária antigênero. IN: Rev. psicol. polít. vol.18 no.43 São Paulo set./dez. 2018. http://pepsic.bvsalud.org/scielo.php?script=sci_arttext\&pid=S1519-549X2018000300004, acesso em: 31 jul 2019.

LANZ, Letícia. O corpo da roupa: a pessoa transgênera entre a transgressão e a conformidade com as normas de gênero. Uma introdução aos estudos transgêneros. Curitiba: Transgente, 2015.

MEYER, Dagmar Elisabeth Estermann e PETRY, Analídia Rodolpho. Transexualidade e heteronormatividade: algumas questões para a pesquisa. IN: Textos \& Contextos (Porto Alegre), v. 10, n. 1, p. 193 -198, jan./jul.2011

PRADO, Marco Aurélio Maximo e CORREA, Sonia. Retratos transnacionais e nacionais das cruzadas antigênero. Editorial. Rev. psicol. polít. vol.18 no.43 São Paulo set./dez. 2018 PONTIFÍCIO Conselho para a Família. Família, matrimônio e "uniões de fato". Cidade do Vaticano, 26 jul. 2000. Disponível em: 〈goo.gl/bhi2RB>. [Port.: goo.gl/riaMiJ]. Acesso em: 10 ago. 2019.

PONTIFÍCIO Conselho para a Família. Lexicon: termini ambigui e discussi su famiglia, vita e questioni etiche. 2. ed. Bologna: Edizioni Dehoniane, 2006. [1. ed.: 2003]. Acesso em: 10 ago. 2019 [trad. livre]

ROSENMANN, Marcos Roitman. Neoliberalismo. IN: Enciclopédia Latinoamerica. http://latinoamericana.wiki.br/, acesso em 03 ago 2019.

SCRUTON, Roger. O que é conservadorismo? Trad. Guilherme Ferreira Araújo. São Paulo: É Realização, 2015.

SEPUlVEDA, Denize e SEPUlVEDA, José Antonio. Conservadorismo, gêneros e sexualidades: temáticas que se entrelaçam nas pesquisas do GESDI e do GEPCEB. In: AMARO, Ivan e SEPULVEDA, Denize (org.). Gêneros, sexualidades e educação na ordem do dia. Curitiba: CRV, 2018, p. 45 a 66.

SILVA, Ivanderson Pereira da Silva. Em busca de significados para a expressão "ideologia de gênero". In: Educ. Rev. . vol.34. Belo Horizonte, 2018, Epub Dec 13, 2018. http://dx.doi.org/10.1590/0102-4698190810, acesso em 24 mar 2019.

SOLANO, Rafael. Ideologia de gênero e a crise da identidade sexual: perguntas e respostas. Cachoeira Paulista - SP: Editora Canção Nova, 2016. 
TRIGUEIRO, Gabriel Romero. Neoconservadorismo versus Paleoconservadorismo: um estudo sobre a genealogia do movimento conservador norte-americano no pós-Segunda Guerra e suas principais disputas identitárias. Orientadora: Sabrina Evangelista Medeiros. Tese (doutorado). Universidade Federal do Rio de Janeiro, Instituto de História, Programa de Pós-Graduação em História Comparada, 2017.

WALLERSTEIN, I. O declínio do poder americano. Rio de Janeiro: Contraponto, 2004. 